\title{
En Route to a Heterogeneous Catalytic Direct Peptide Bond Formation by Zr-based Metal-Organic Framework Catalysts
}

Francisco de Azambuja ${ }^{\ddagger}$, Alexandra Loosen ${ }^{\ddagger}$, Dragan Conic ${ }^{\ddagger}$, Maxime van den Besselaar, Jeremy N. Harvey and Tatjana N. Parac-Vogt*

Department of Chemistry, KU Leuven, Celestijnenlaan 200F, 3001 Leuven, Belgium

\section{*tatjana.vogt@kuleuven.be}

$¥$ Contributed equally to this work.

\section{TOC}

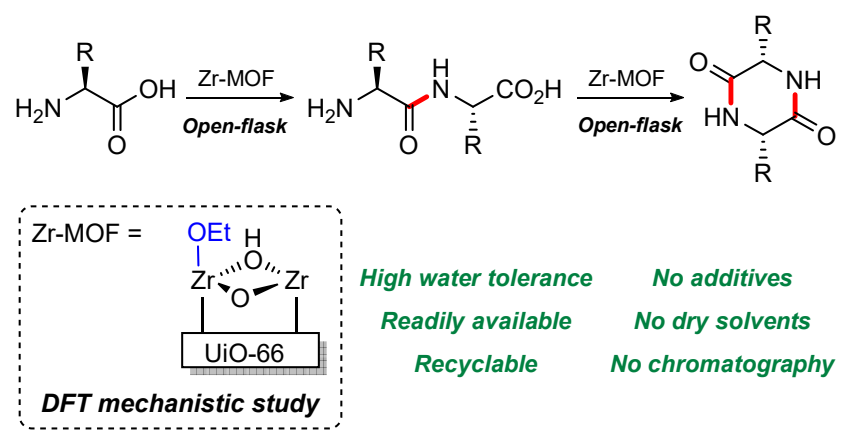

\begin{abstract}
Peptide bond formation is a challenging, environmentally and economically demanding transformation. Catalysis is key to circumvent current bottlenecks. To date, many homogeneous catalysts able to provide synthetically useful methods have been developed, while heterogeneous catalysts remain largely restricted to the studies addressing the prebiotic formation of peptides. Here, the catalytic activity of $\mathrm{Zr}_{6}$-based metalorganic frameworks (Zr-MOFs) towards the peptide bond formation is investigated using the dipeptide cyclization as a model reaction. Unlike previous catalysts, Zr-MOFs largely tolerate water, and reactions are carried out under ambient conditions. Notably, the catalyst is recyclable and no additives to activate $\mathrm{COOH}$ group are necessary, which are common limitations of previous methods. In addition, broad reaction scope tolerates substrates with bulky and Lewis basic groups. The reaction mechanism was assessed by detailed mechanistic and computational studies, and features a Lewis acid activation of carboxylate group by $\mathrm{Zr}$ center towards amine addition, in which an alkoxy ligand on adjacent $\mathrm{Zr}$ site assists lowering the barrier of key proton transfers. The proposed concepts were also used to study the formation of
\end{abstract}


intermolecular peptide bond formation. While intrinsic challenges associated with the catalyst structure and water removal limit a more general intermolecular reaction scope under current conditions, the results suggest that further design of Zr-MOF catalysts could render these materials broadly useful as heterogeneous catalysts for this challenging transformation.

KEYWORDS: Metal organic frameworks, synthesis, zirconium, amide bond, peptide bond, diketopiperazines, peptide synthesis, peptide bond formation. 


\section{Introduction}

The synthesis of amides is a frequent task in every chemical laboratory. However, common procedures suitable to small laboratory scale fail to meet demanding industrial requirements. ${ }^{1-3}$ Likewise, peptide bond formation is even more challenging due to the lower reactivity of the amino acid $\mathrm{NH}_{2}$ group compared to regular amines. ${ }^{4}$ In these reactions, carboxylic acids usually require additional steps and/or reagents to facilitate $\mathrm{NH}_{2}$ attack, substantially decreasing process efficiency by increasing waste generation and energy consumption. Catalysis has been explored as an alternative to streamline amide synthesis, resulting in amide bond formations directly from non-activated carboxylic acids and amines catalyzed mainly by boron ${ }^{5}$ and group IV/V metal ${ }^{6-9}$ catalysts. ${ }^{10}$ Notably, catalytic peptide bond formation remains underdeveloped, despite advancements featuring boron-,${ }^{11-13}$ metal- $^{14-15}$ and organocatalysts ${ }^{16}$ reported recently. Although promising, these catalytic systems still require water removal from the reaction to provide good yields, making their re-use practically and economically challenging for wider industrial applications. ${ }^{1,4}$ Recently, we have shown that embedding $\mathrm{Zr}$ (IV) or $\mathrm{Hf}(\mathrm{IV})$ cations into anionic oxo clusters imparts an unusual water tolerance to the catalytic reaction, allowing formation of amide bonds under mild conditions with great experimental simplicity, and potential re-use of the catalyst. ${ }^{17-18}$ Here, we extend this concept by using $\mathrm{Zr}(\mathrm{IV}$ )-oxo clusters embedded in metal organic frameworks (MOFs) as convenient and tailorable heterogeneous catalysts for the peptide bond formation.

The synthesis of amides directly from non-activated carboxylic acids and amines using heterogeneous catalysts is still of limited utility to synthetic chemists, despite numerous studies that have been done in the past. ${ }^{10}$ Most reactions are limited to formylation and acylation reactions, with few examples reporting more general substrates. ${ }^{19-22}$ Generally, these heterogenous catalysts afford amides under similar conditions to those used by homogeneous catalysts, that is, under (azeotropic) reflux at temperatures above $100{ }^{\circ} \mathrm{C}$ in anhydrous conditions. In addition, many of the heterogeneous catalysts reported so far consisted of commercially available inorganic oxides like $\mathrm{Nb}_{2} \mathrm{O}_{5}, \mathrm{Al}_{2} \mathrm{O}_{3}, \mathrm{Zr}_{2} \mathrm{O}, \mathrm{TiO}_{2}, \mathrm{SiO}_{2}$, etc, precluding control over the molecular environment surrounding the catalytic sites. ${ }^{19,23-25}$ Attempts to rationally design inorganic matrixes doped with catalytically active metals have been done, ${ }^{22}$ but despite recent advances in the areas of surface organometallic and single-atom catalysis, ${ }^{26-27}$ tuning and designing heterogeneous catalysts at the molecular level remains a very challenging task, which limits to some extent the substrate scope expansion through a more rational design of novel catalysts. On the other hand, metal-organic frameworks (MOFs) have emerged as a powerful new class of heterogeneous catalysts. ${ }^{28-32}$ Strikingly different from other common heterogeneous materials, MOFs are intrinsically porous and highly tailorable organic-inorganic hybrid materials prepared through the controlled assembly of distinct metal clusters and specially designed 
organic linkers. ${ }^{33}$ Moreover, an increasing number of methods allow engineering defects to fine-tune desired catalytic properties. ${ }^{34-36}$ However, the use of MOFs in the amide bond formation remains elusive, ${ }^{2,37}$ despite the successful reports of MOFs as catalysts in esterification reactions. ${ }^{38-42}$ So far only a single MOFcatalyzed amide bond formation has been reported focusing on the utility of a newly synthesized MOF material using previously reported conditions; however, this study provided little mechanistic insights that could allow further development of such chemistry. ${ }^{43}$

Recently, our work intersected with MOF catalysis due to our interest in developing heterogeneous artificial peptidases based on metal-oxo clusters. ${ }^{44-45}$ To this end, we have pioneered the peptidase activity of $\mathrm{Zr}_{6} \mathrm{O}_{8}$ cluster-centered MOFs (Zr-MOFs) using MOF-808, ${ }^{46-47}$ NU-1000, ${ }^{48}$ and UiO-66 ${ }^{49}$ as catalysts. Among other practical advantages, these Zr-MOFs provided much higher hydrolysis rates than our previous $\mathrm{Zr}(\mathrm{IV}) / \mathrm{Hf}(\mathrm{IV})$-polyoxometalate catalysts, prompting us to further evaluate if Zr-MOFs could also work in the reverse direction and lead to the formation of peptide bonds instead of its cleavage, as we observed previously for $\mathrm{Zr}(\mathrm{IV}) / \mathrm{Hf}(\mathrm{IV})$-polyoxometalate complexes. ${ }^{17}$ Prior works addressing the formation of peptide bonds through heterogeneous catalysis have been mostly related to the prebiotic formation of peptides. ${ }^{50-54}$ They provided extensive mechanistic understanding on the interaction between amino acids and peptides with oxide surfaces, particularly silica, and the formation of peptide bonds in these environments. ${ }^{55-57}$ The formation of peptide products has been generally observed at temperatures which exceeded $100{ }^{\circ} \mathrm{C}$. Moreover, products were frequently generated as mixtures, and were usually not isolated and purified, thereby drastically limiting the synthetic potential of these reactions for preparative organic chemistry. ${ }^{58}$ Therefore, in view of the great structural versatility and stability, ${ }^{59-60}$ the increasing utility of Zr-MOFs in catalysis, ${ }^{61}$ and the lack of more general heterogeneous catalysts for the catalytic direct formation of amide and peptide products, ${ }^{10,19-22,43}$ repurpose of Zr-MOFs from hydrolysis to formation of peptide bonds would greatly contribute to develop a truly sustainable and practical peptide bond formation method. In this context, we report the formation of peptide bonds catalyzed by UiO-66 MOF. Inspired by our previous work, ${ }^{17,46-49}$ we used the dipeptide cyclization to develop and explore the catalytic activity of Zr-MOFs towards intramolecular peptide bond formation. Furthermore, we explored the reaction mechanism by theoretical and experimental approaches, which unveiled key advantages of the multimetallic nature of the Zr-oxo cluster to the reactivity observed. Initial results towards the intermolecular peptide bond formation reaction are also presented. 


\section{Results and discussion}

Reaction optimization. To develop Zr-MOFs as catalysts for the formation of peptide bonds, we have started our work by studying the cyclization of dipeptides in the presence of Zr-MOFs, following our previous successful strategy in which the hydrolytic activity of $\mathrm{Zr}(\mathrm{IV}) / \mathrm{Hf}(\mathrm{IV})$-polyoxometalate complexes was repurposed to an amide bond formation reaction upon rational adjustment of the reaction conditions. ${ }^{17-}$ ${ }^{18}$ Thus, the cyclization of glycylglycine (1a) to 2,5-diketopiperazine (2a) was evaluated in various solvents upon incubation of $1 \mathbf{a}$ with different Zr-MOFs, which were previously shown to be catalytically active for the peptide bond hydrolysis (Table 1 ). ${ }^{46,}{ }^{48-49}$ Based on our previous work, ${ }^{17}$ we used DMSO as a representative organic solvent to test three well-known and easily prepared Zr-MOFs with varying characteristics: 1) MOF-808, a 6-connected MOF with 1,3,5-benzenetricarboxylate linkers; ${ }^{62}$ 2) NU-1000, a 8-connected MOF with 1,3,6,8-(p-benzoate)pyrene linkers; ${ }^{63}$ and 3) $\mathrm{UiO}$-66, a nominally 12-connected MOF with 1,4-benzenedicarboxylate (BDC) linkers. ${ }^{64}$ The presence of free carboxylic acid groups in our substrate could result in adsorption of substrates or the resulting products to the MOF catalyst. Therefore, we have employed a 'washing step' after the reaction to ensure full material recovery. Using MOF-808 as a representative structure, we observed that stirring the crude reaction mixture for $1 \mathrm{~h}$ with $\mathrm{D}_{2} \mathrm{O}$ generally ensured a high recovery of material (>95\%). We have standardized such step through all the reaction discovery and optimization stages (Table S1).

In these initial reactions using DMSO as solvent, MOF-808 and UiO-66 provided 2a in higher yields than NU-1000 (Figures S4-S5), likely due to the lower recovery of material observed for NU-1000 (<20\%). MOF-808 formed 2a in 50\% yield, but a small fraction of glycine (Gly, 3a) was also detected probably arising from peptide bond hydrolysis with residual water present in the MOF structure and/or solvent (Table 1). ${ }^{46}$ On the other hand, despite the lower yield, UiO-66 cleanly converted 1a into $2 a$ (33\% yield). Considering that MOF-808 and UiO-66 MOF allowed for an easier recovery of substrate and products in our system, further investigation focused on these MOFs only. 
Table 1: Cyclization of GlyX (1a,b) to cyclo(GlyX) (2a,b) is affected by the MOF structure, solvent, temperature and catalyst loading.

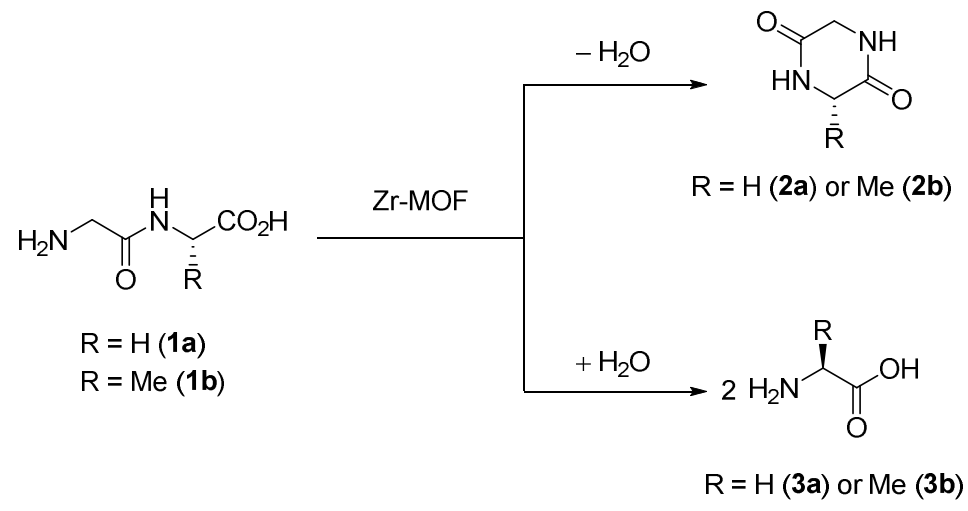

\begin{tabular}{|c|c|c|c|c|c|c|c|c|}
\hline \multirow[b]{2}{*}{ Entry } & \multirow[b]{2}{*}{$\mathbf{R}$} & \multirow[b]{2}{*}{ MOF } & \multirow[b]{2}{*}{ mol\% } & \multirow[b]{2}{*}{ Solvent } & \multirow[b]{2}{*}{$\mathbf{T}\left({ }^{\circ} \mathbf{C}\right)$} & \multicolumn{3}{|c|}{ Yield $(\%)^{a}$} \\
\hline & & & & & & 1a,b & 2a,b & 3a,b \\
\hline 1 & $\mathrm{H}$ & MOF-808 & 10 & DMSO & 80 & 50 & 48 & 2 \\
\hline 2 & $\mathrm{H}$ & UiO-66 & 10 & DMSO & 80 & 65 & 33 & 0 \\
\hline 3 & $\mathrm{H}$ & MOF-808 & 10 & $\mathrm{MeOH}$ & 80 & 29 & 59 & 4 \\
\hline 4 & $\mathrm{H}$ & UiO-66 & 10 & $\mathrm{MeOH}$ & 80 & 0 & 100 & 0 \\
\hline 5 & $\mathrm{Me}$ & UiO-66 & 10 & $\mathrm{MeOH}$ & 80 & 0 & 100 & 0 \\
\hline 6 & $\mathrm{Me}$ & UiO-66 & 10 & $\mathrm{EtOH}$ & 80 & 0 & 100 & 0 \\
\hline 7 & $\mathrm{Me}$ & UiO-66 & 10 & ${ }^{n} \mathrm{PrOH}$ & 80 & 0 & 100 & 0 \\
\hline 8 & $\mathrm{Me}$ & UiO-66 & 10 & ${ }^{i} \mathrm{PrOH}$ & 80 & n.a. ${ }^{e}$ & 58 & 0 \\
\hline 9 & $\mathrm{Me}$ & UiO-66 & 10 & $\mathrm{MeOH}$ & 70 & 8 & 92 & 0 \\
\hline 10 & $\mathrm{Me}$ & UiO-66 & 10 & $\mathrm{MeOH}$ & 60 & 35 & 65 & 0 \\
\hline $11^{b}$ & $\mathrm{H}$ & UiO-66 & 10 & $\mathrm{MeOH}$ & 80 & 0 & 100 & 0 \\
\hline $12^{c}$ & $\mathrm{H}$ & UiO-66 & 10 & $\mathrm{MeOH}$ & 80 & 6 & 94 & 0 \\
\hline $13^{d}$ & $\mathrm{Me}$ & UiO-66 & 2 & $\mathrm{MeOH}$ & 80 & 0 & 100 & 0 \\
\hline
\end{tabular}

Conditions: $0.100 \mathrm{mmol}$ 1a,b, $10.0 \mathrm{~mol} \% \mathrm{MOF}$, solvent $(0.10 \mathrm{~mol} \mathrm{~L}-1), 24 \mathrm{~h} .{ }^{a}$ Based on ${ }^{1} \mathrm{H}-\mathrm{NMR} .{ }^{b} 0.05 \mathrm{~mol} \mathrm{~L}{ }^{-1} .{ }^{c} 0.20$ mol L-1. ${ }^{d} 168$ h. ${ }^{e} \mathrm{H}_{\mathrm{NMR}}$ peaks of $\mathbf{1 b}$ overlapped with solvent.

Following the initial screening, other solvents were probed using MOF-808 and UiO-66, identifying alcohols as optimal reaction solvents. Generally, MOF-808 adsorbed substrate and products more strongly than UiO-66, as observed by the mass recovery $<75 \%$ for solvents other than $\mathrm{MeOH}$ and DMSO for MOF808. For UiO-66, only $\mathrm{MeCN}: \mathrm{H}_{2} \mathrm{O}$, toluene and dioxane reactions resulted in $<90 \%$ mass recovery for those ones carried out in organic medium (Figure S4-S5). Moreover, MOF-808 showed again a greater tendency than UiO-66 to hydrolyze 1a, as evident from the results in solvents containing water. On the other hand, 
UiO-66's enhanced selectivity towards $2 \mathbf{a}$ was once more observed for the reaction in $\mathrm{MeOH}$, which provided only desired product 2a and no side hydrolysis reaction (entry 4, Table 1). To test other alcohols, we used GlyAla (1b) instead of GlyGly (1a) to avoid overlap between product and solvent peaks in the ${ }^{1} \mathrm{H}$ NMR. The minimal structural changes do not affect reactivity as both substrates smoothly provide the desired cyclic adduct $\mathbf{2 a}, \mathbf{b}$ in $>99 \%$ in $\mathrm{MeOH}$. Using $\mathbf{1 b}$, ethanol and 1-propanol also provided $\mathbf{2 b}$ in $>99 \%$ yield, while isopropanol resulted in only $\sim 60 \%$ yield, suggesting smaller and linear alcohols are preferred as reaction solvents (entries 5-8, Table 1), though overlapped signals in the crude ${ }^{1} \mathrm{H}$ NMR hampered us to establish whether the lower yield in isopropanol derives from lower conversion or simply from the lower mass recovery in this reaction.

In general, the low mass recovery observed in some cases seems to be related to the available uncoordinated $\mathrm{Zr}$ sites, and the ability of solvent to reverse the binding of substrates and products to these sites, since lower mass recovery was generally observed for MOF-808 and NU-1000 in comparison with UiO-66. Similarly, lower mass recovery was also observed when cyclization was carried out in solvents that poorly solubilize 1a,b/2a,b (e.g., dioxane and toluene for UiO-66). These trends strongly suggests that the interplay between available $\mathrm{Zr}$ sites and the ability of the solvent to reverse substrates and products presumed coordination to these sites plays a key role in the overall process efficiency. When more $\mathrm{Zr}$ sites are available, more substrate/product molecules bind to the MOF, and if the solvent is not able to efficiently reverse this trend, a lower mass recovery is observed. Such hypothesis is also consistent with the better, but rather intriguing performance of UiO-66 for the cyclization of 1a,b in comparison with MOF-808 and NU-1000 MOFs, which intrinsically have more uncoordinated $\mathrm{Zr}$ sites than UiO-66. Together, these results show that the connectivity and missing-linker defects alone do not guarantee higher reaction yield as commonly indicated in the literature, since the adsorption of substrates and products to the MOF material and the ability of the solvent to reverse it directly affects the overall mass recovery after the reaction, subsequently impacting the reaction yield. Interestingly, use of water as a reaction solvent resulted in the lowest recoveries for MOF808 and UiO-66, suggesting solubility is likely not the only factor involved in overcoming material adsorption.

Further optimization was performed by probing the effect of temperature, concentration and catalyst loading for the reaction using UiO-66 in methanol. Lower temperature decreased reaction efficiency. At $70{ }^{\circ} \mathrm{C}, \mathbf{2 b}$ yield slightly decreased, and it significantly dropped for temperatures of $60^{\circ} \mathrm{C}$ or lower (entries 9-10, Table 1 and Table S2). In addition, dilution or concentration of the reaction did not significantly affected efficiency (entries 11-12, Table 1 and Table S3). Finally, lower catalyst loadings also provided 2b in quantitative yields, although slower rates were observed (Table S4). Using 2 mol\% of UiO-66, 2b was formed in 33\% 
yield after $24 \mathrm{~h}$. However, a longer reaction time of $168 \mathrm{~h}$ provided quantitative yield, indicating the catalyst is not deactivated by side-processes even after considerably long reaction time (entries 13, Table 1). This robust profile is usual for Zr-MOFs, but is unparalleled to other metal catalysts for the amide bond formation, and further highlights the excellent catalytic potential of Zr-MOFs for the peptide bond formation.

Control experiments. Control experiments confirmed the superiority of UiO-66 as a heterogeneous catalyst for the intramolecular peptide bond formation. In the absence of UiO-66, and when using Zr salts or BDC ligand separately, reaction yields were $<10 \%$ (Table S5). Notably, soluble $\operatorname{Zr}\left({ }^{i} \operatorname{PrO}\right)_{4}$ and a combination of $\mathrm{ZrCl}_{4}$ and BDC resulted in good yields of $\mathbf{2 b}$, though lower than with UiO-66. The performance of $\mathrm{Zr}\left({ }^{i} \mathrm{PrO}\right)_{4}$ and $\mathrm{ZrCl}_{4} / \mathrm{BDC}$ was attributed to a putative formation of $\mathrm{Zr}$-oxo clusters in situ, which also points to the key catalytic role of UiO-66's $\mathrm{Zr}_{6}$ clusters. ${ }^{65-66}$ Additionally, control experiments using drying agents provided low yields of $\mathbf{2 b}$, strongly indicating that the water adsorption ability of MOF is likely not reposnsible for the observed reactivity (Table S5). Finally, absence of reaction upon removal of catalyst, along with UiO-66's stability observed in this work, strongly indicates that the catalysis is heterogeneous in nature (Figure S6).

Stability, recyclability and water-tolerance of UiO-66 catalyst. Additional experiments confirmed the catalyst stability, and prompted us to probe the UiO-66 recyclability and tolerance of catalyst to water. UiO66's excellent structural stability was confirmed through scanning electron microscopy (SEM) (Figure 1a), powder X-ray diffraction (PXRD), infrared spectroscopy (FT-IR), and thermal gravimetric analysis (TGA) of catalyst samples that were easily recovered by centrifugation from experiments with 1a,b (Figures S7S9). Additionally, ICP-OES revealed very little leaching of $\mathrm{Zr}(\mathrm{IV})$ ions into solution (only $0.004 \%$ ) confirming its structural stability and heterogeneous nature of the reaction. Further, MOF digestion revealed $\sim 5 \%$ of $\mathbf{1 b}$ and $\mathbf{2 b}$ after the reaction, indicating that minor amounts of the substrate and product remain adsorbed to the catalyst (Figures S11-S12). This suggests non-negligible changes to the pore and surface of UiO-66 after the reaction and simple $\mathrm{MeOH}$ washing steps. Thus, recovered UiO-66 was washed with $\mathrm{D}_{2} \mathrm{O}$ and $\mathrm{MeOH}$ to remove traces of starting material and product before drying and re-using in a new reaction. This recycling protocol effectively afforded $\mathbf{2 b}$ in $>97 \%$ yield over 5 cycles (Figure $1 \mathrm{~b}$ and Table S6), while no structural changes in MOF's crystalline network were detected by PXRD analysis (Figure 1c). 
a)

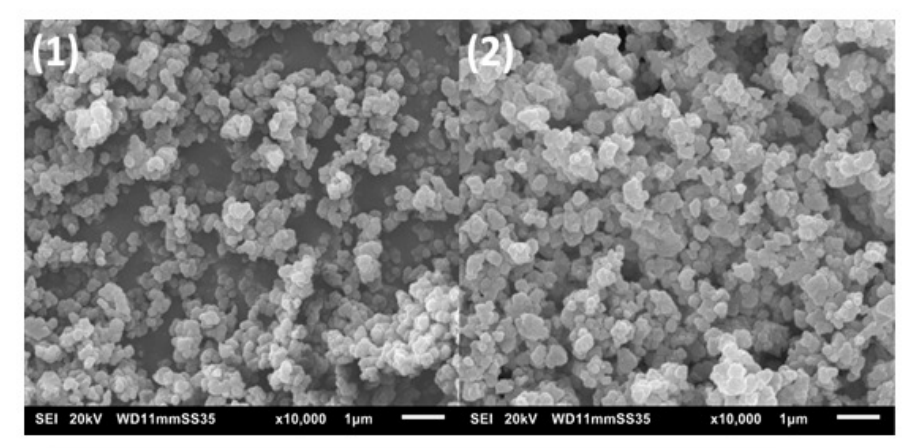

b)

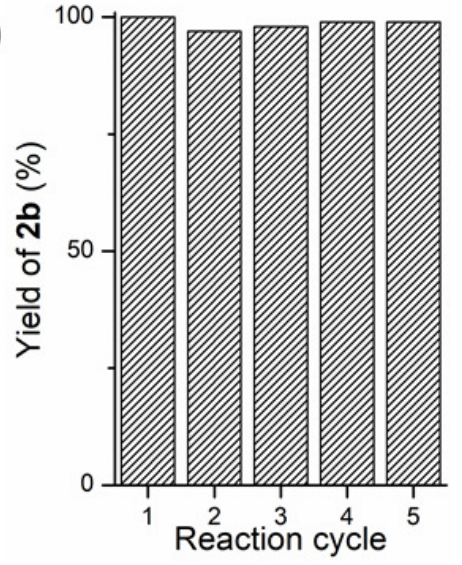

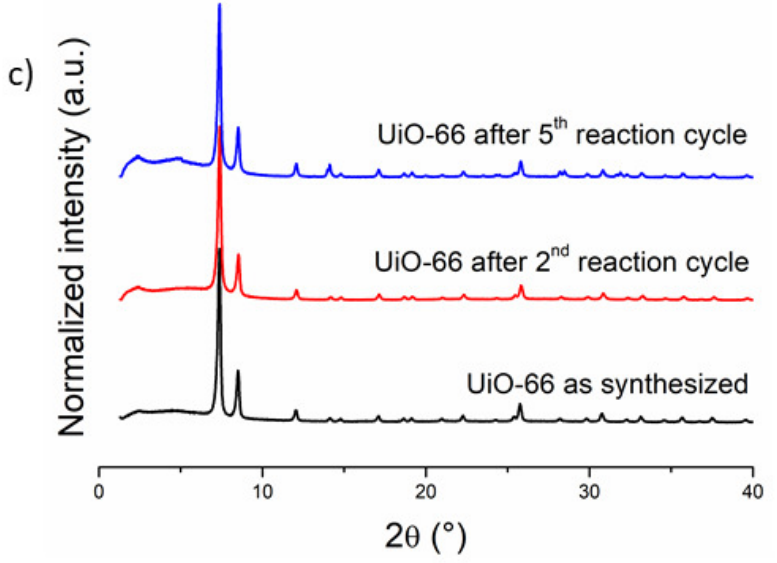

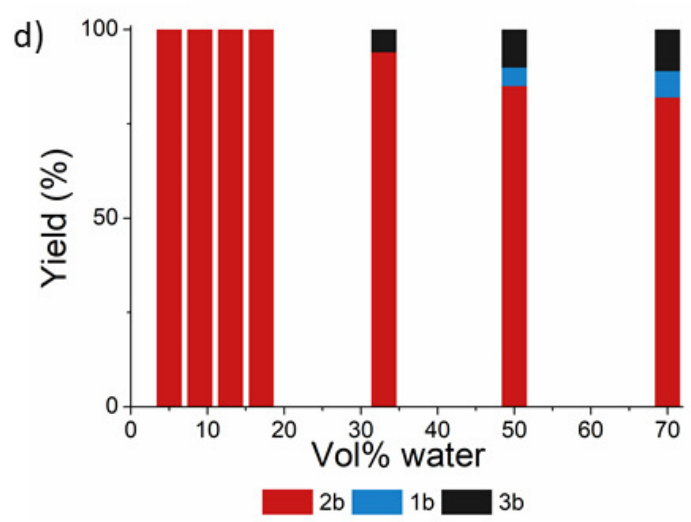

Figure 1: UiO-66 is a stable and recyclable catalyst with high tolerance towards water: (a) SEM images of (1) UiO66 as synthesized and (2) after reaction with $0.100 \mathrm{mmol} \mathbf{1 b}, 80^{\circ} \mathrm{C}, 24 \mathrm{~h}, \mathrm{MeOH}$. (b) UiO-66 affords the same yields of $\mathbf{2 b}$ after five reaction cycles. (c) PXRD pattern of UiO-66 as synthesized (black), and after two (red) and five (blue) reaction cycles with $0.100 \mathrm{mmol} \mathbf{1 b}, 80^{\circ} \mathrm{C}, 24 \mathrm{~h}$ and solvent exchange with $\mathrm{D}_{2} \mathrm{O}$ and $\mathrm{MeOH}$. (d) UiO-66 maintains its high catalytic performance even after addition of large amounts of external water.

UiO-66 catalytic cyclization of $\mathbf{1 b}$ tolerates uniquely large amounts of water, and $>95 \%$ yield is observed in the presence of nearly 2800 molar excess of water with respect to the catalyst (Figure 1d and Table S7). UiO-66's stability prompted us to check its tolerance to the presence of water in the reaction, as watersensitivity sharply limits large scale catalytic amide bond formations. ${ }^{1-2,4}$ By adding increasing amounts of water to the standard reaction, $>97 \%$ yield of $\mathbf{2 b}$ was observed up until $27.8 \mathrm{mmol}$ of $\mathrm{D}_{2} \mathrm{O}(33 \%$ of reaction volume in Figure 1d), which corresponds to a remarkable 2778-fold excess related to the catalyst (Table S7). Further reactions showed that this tolerance is related to the amount of $\mathrm{MeOH}$, and lower yields were observed when $\mathrm{MeOH}$ volume was reduced proportionally to the water added in order to keep reaction concentration constant. However, even when water corresponded to $70 \%$ of the solvent, a respectable $82 \%$ yield of $\mathbf{2 b}$ is still observed. Such results also strongly suggest the minor contribution of water segregating ability of MOF in driving the reaction equilibrium forward, in agreement with control experiments. A 
maximum water absorption for $\mathrm{UiO}-66$ of $0.55 \mathrm{~g} \mathrm{H}_{2} \mathrm{O} / \mathrm{g}$ MOF has been reported, ${ }^{67}$ which would mean that to adsorb the $70 \%$ water volume used in the referred reaction $(\sim 0.7 \mathrm{~g})$, a much higher catalytic loading $(\sim 1.3$ $\mathrm{g}$ of MOF, $\sim 800 \mathrm{~mol} \%)$ than the one used here (17 $\mathrm{mg}, 10 \mathrm{~mol} \%$ ) would be needed.

UiO-66 advantageous robustness in the presence of water was further confirmed by its better performance compared to other water tolerant Lewis acid metal salts under the same conditions (Table S8) ${ }^{68}$ When external water was added to the reaction catalyzed by $\operatorname{Zr}\left(\mathrm{O}^{\mathrm{i}} \operatorname{Pr}\right)_{4}(20 \%$ of reaction volume), the good yield previously observed for $\mathbf{2 b}$ in the aforementioned control experiments decreased by $\sim 30 \%$, which is consistent with general sensitivity of $\mathrm{Zr}$ (IV) salts to moisture, given their highly favored hydrolysis to form oligomeric catalytically inactive species. ${ }^{10,69}$ However, PXRD analysis of UiO-66 after reaction conducted in the presence of $50 \% \mathrm{v} / \mathrm{v}$ of water proved the stability of its overall structure under these conditions (Figure S13), demonstrating an intrinsic advantage of the Zr-based MOFs robustness over conventional Zr catalysts based on metal salts or complexes thereof. In addition, other Lewis acids that have been reported to tolerate water have also been tested in the presence and in the absence of water (Table S8). Even for these simple reactions, a general drop of $20-30 \%$ of yield was observed, with the best performing $\mathrm{Sc}(\mathrm{OTf})_{3}$ providing $\mathbf{2 b}$ in $80 \%$ of yield in the presence of $33 \%$ volume of water, while UiO-66 affords $\mathbf{2 b}$ in $97 \%$ of yield under the same conditions. Considering the higher natural abundance of zirconium compared to the other the Lewis acid metal salts tested ( $\mathrm{Ti}$ excluded), and the recyclability exhibited by UiO-66, these results underline a promising prospect of Zr-MOFs, even when one contrasts the complexity of these materials with simple, commercially available metal salts.

Reaction Scope. Several other substrates were successfully shown to undergo cyclization and could be isolated in good to excellent yields, showcasing that UiO-66 MOF catalyst can be applied to substrates bearing diverse functional groups (Table 2), which is essential for later development of intermolecular peptide bond forming methods catalyzed by Zr-MOFs. Standard substrate 1b and Gly-Phe (1c) afforded product $\mathbf{2 b}$ and $\mathbf{2 c}$ in high purity and excellent isolated yields after a simple centrifugation and evaporation

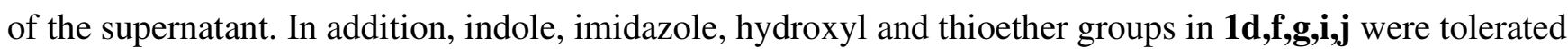

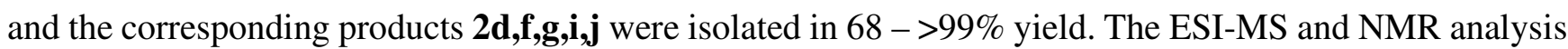
of reactions using Gly-Lys and Gly-Arg dipeptides suggested that these substrates could also undergo cyclization; however, we could not isolate and characterize the corresponding products with our current protocol. Nevertheless, these results point to an overall good compatibility with Lewis basic functional groups. 
Some steric hindrance was also tolerated since Gly-Pro (1e), a secondary amine, and the bulky side chain of Gly-Leu (1h) afforded products $\mathbf{2 e}$ and $\mathbf{2 h}$ in 92 and $>99 \%$ respectively. Similar $\mathbf{2 b}$ and $\mathbf{2 e}$ yields were obtained when glycine was moved to the C-terminal position of the dipeptide substrate, while a significant drop was observed for Ser-Gly (1f) (45\%), likely due to a non-productive coordination of the hydroxyl moiety. Even Ala-Ala (1i), a dipeptide without a glycine residue, was cyclized to $2 \mathbf{i}$ in 18 and $33 \%$ yield after 24 and 96 h, respectively. Unnatural amino acids 11,m were also successfully cyclized, showing the proteogenic nature of the substrate is not required for observing the reactivity.

Our attempts to cyclize longer oligomers such as tri-, tetra-, and pentaglycine, or unnatural amino acids with distinct carbon chain lengths (4, 6 and 7) under the same conditions were unfortunately not successful. For most cases, neither substrates or products were observed after reactions, suggesting that the substrates remained adsorbed to the catalyst, which is consistent with the significant adsorption of longer peptides (e.g., proteins) to metal oxo cluster observed in our previous works. ${ }^{44,48}$ In general, cyclized products also showed different affinities for the MOF catalyst, including extreme cases like Gly-Asp (1n) and Gly-Glu (10) which even leads to partial loss of the crystallinity rather than cyclization (Figure S14). Thus, in some cases additional washings of the catalyst to remove the products were necessary. However, although not fully optimized, our isolation protocol afforded the cyclized products in good to excellent purity, and no liquid-liquid extraction or chromatographic purification was necessary. 
Table 2: Intramolecular amide bond formation from dipeptides and other amino acid substrates.

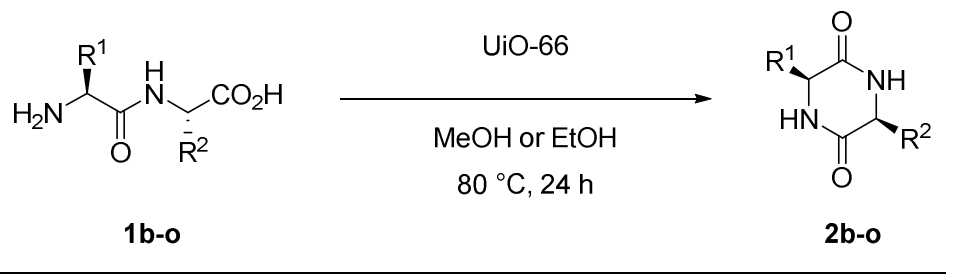<smiles>CC1NC(=O)CNC1=O</smiles>

2b<smiles>O=C1CNC(=O)[C@H](Cc2ccccc2)N1</smiles>

2c, $88 \%$<smiles>O=C1CNC(=O)[C@H](Cc2c[nH]c3ccccc23)N1</smiles>

2d, $81 \%$

from Gly-Ala: $96 \%$ from Ala-Gly: $87 \%$<smiles>O=C1NCC(=O)N2CCC[C@H]12</smiles>

2e

from Gly-Pro: $92 \%$ from Pro-Gly: $88 \%$<smiles>CC(C)C[C@@H]1NC(=O)CNC1=O</smiles>

2h, $>99 \%$<smiles>[CH2]C1NC(=O)C(C)NC1=O</smiles>

2k, $18 \%\left(33 \%^{a}\right)^{b}$<smiles>O=C1CNC(=O)[C@H](CO)N1</smiles>

$2 f$

from Gly-Ser: $91 \%$ from Ser-Gly: $45 \%$<smiles>CC(O)C1NC(=O)CNC1=O</smiles>

$2 \mathrm{i}, 82 \%$<smiles>O=C1CCCC1</smiles>

$2 \mathrm{I} \mathrm{n}=1,97 \%^{b}$ $2 \mathrm{~m} \mathrm{n}=2,98 \%^{b}$<smiles>O=C1CNC(=O)[C@H](Cc2c[nH]cn2)N1</smiles>

2g, $74 \%$<smiles>CSCC[C@H]1NC(=O)CNC1=O</smiles>

$\mathbf{2 j},>99 \%$<smiles>O=C(O)CC1NC(=O)CNC1=O</smiles>

2n $\mathrm{n}=1,0 \%$ 2o $n=2,0 \%$

Conditions: 1b-o (0.100 - $0.500 \mathrm{mmol}), 10.0 \mathrm{~mol} \% \mathrm{UiO}-66, \mathrm{MeOH}$ or $\operatorname{EtOH}\left(0.10 \mathrm{~mol} \mathrm{~L}^{-1}\right), 80{ }^{\circ} \mathrm{C}, 24 \mathrm{~h}$. Isolated yields. ${ }^{a} 96 \mathrm{~h}$ reaction. ${ }^{b}$

${ }^{1} \mathrm{H}$ NMR yields.

Reaction mechanism. To gain a better understanding of the catalyst activity, we carried out a detailed experimental and theoretical investigation of the reaction mechanism. Based on our own work, ${ }^{46-49,70}$ previous reports on $\mathrm{Zr}$-catalyzed formation of amides directly from non-activated carboxylic acids and amines, ${ }^{17,71}$ and control experiments reported here, we suggest a general Lewis acid catalytic pathway for this intramolecular amide bond formation in which the dipeptide carboxylate group is activated through 
coordination to a $\mathrm{Zr}$ open site of the MOF (Figure 2). However, the reasons for the superior reactivity observed in alcoholic solvents were not clear at the beginning since only the solvent influence in the mass recovery discussed above does not explain why the yield of $\mathbf{2 a , b}$ in $\mathrm{MeOH}$ or EtOH is much higher when UiO-66 MOF is used as a catalyst in comparison to when MOF-808 is employed, given that $>95 \%$ of the initial mass is recovered with both catalyst (Figures S4 and S5). Such observation prompted us to further investigate whether the alcoholic solvent plays an additional role in the mechanism. Thus, we investigated whether both a superior proton transfer ability of alcoholic solvents inside the pores of UiO- $66^{72}$ or the formation of an intermediate ester ${ }^{73}$ could explain the reactivity observed.

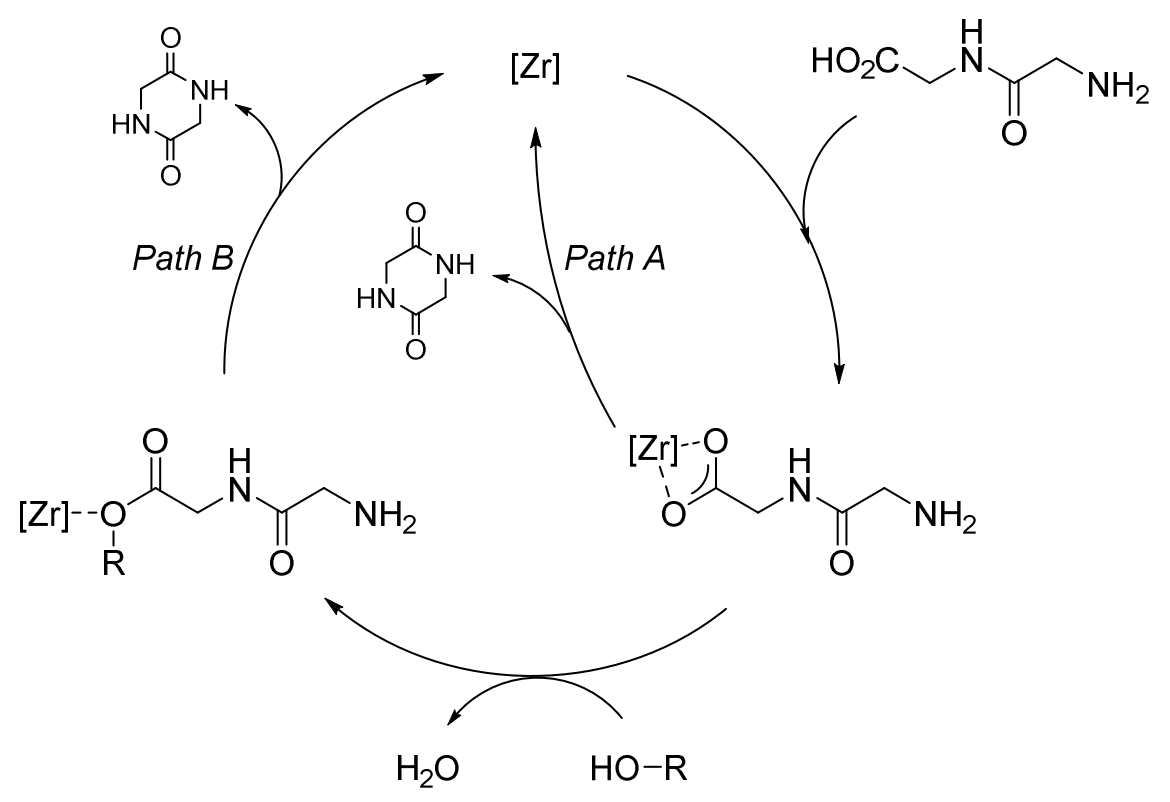

Figure 2: Mechanistic possibilities for the Zr-MOF catalyzed intramolecular peptide bond formation

Reaction kinetics. Different kinetic experiments were used to get a clearer picture of the catalyst activity, such as potential inhibition and involvement of intermediates. Substrate consumption directly leads to product formation judging by the mirrored aspect of the kinetic profile of $\mathbf{1 b}$ cyclization, disfavoring a reaction pathway involving a potential intermediate product (Figure 3a). Using a pseudo first-order kinetics model, a rate constant of $1.54 \times 10^{-4} \mathrm{~s}^{-1}$ and a half-life of $1.2 \mathrm{~h}$ were obtained at $80{ }^{\circ} \mathrm{C}$ (Figure $3 \mathrm{~b}$ ). Upon increasing the temperature from $60{ }^{\circ} \mathrm{C}$ to $90{ }^{\circ} \mathrm{C}, \mathrm{a} \approx 17$-fold reduction of the half-life from 16 hours at 60 ${ }^{\circ} \mathrm{C}$ to only 0.9 hours at $90{ }^{\circ} \mathrm{C}$ was observed (Figure S15a). Fitting these data to the Eyring equation, we estimated $\Delta G^{\ddagger}=27.2 \mathrm{kcal} \mathrm{mol}^{-1}$ at $80{ }^{\circ} \mathrm{C}\left(\Delta H^{\ddagger}=22.9 \mathrm{kcal} \mathrm{mol}^{-1}, \Delta S^{\ddagger}=-12.1 \mathrm{cal} \mathrm{mol}^{-1} \mathrm{~K}^{-1}\right)$ (Figure S15b). Finally, control kinetic experiments in which the MOF is pre-saturated with product $\mathbf{2 b}$ showed no 
difference in yield after 3 and $5 \mathrm{~h}$ in comparison with the non-inhibited reaction, suggesting no product inhibition happens (Table S10).
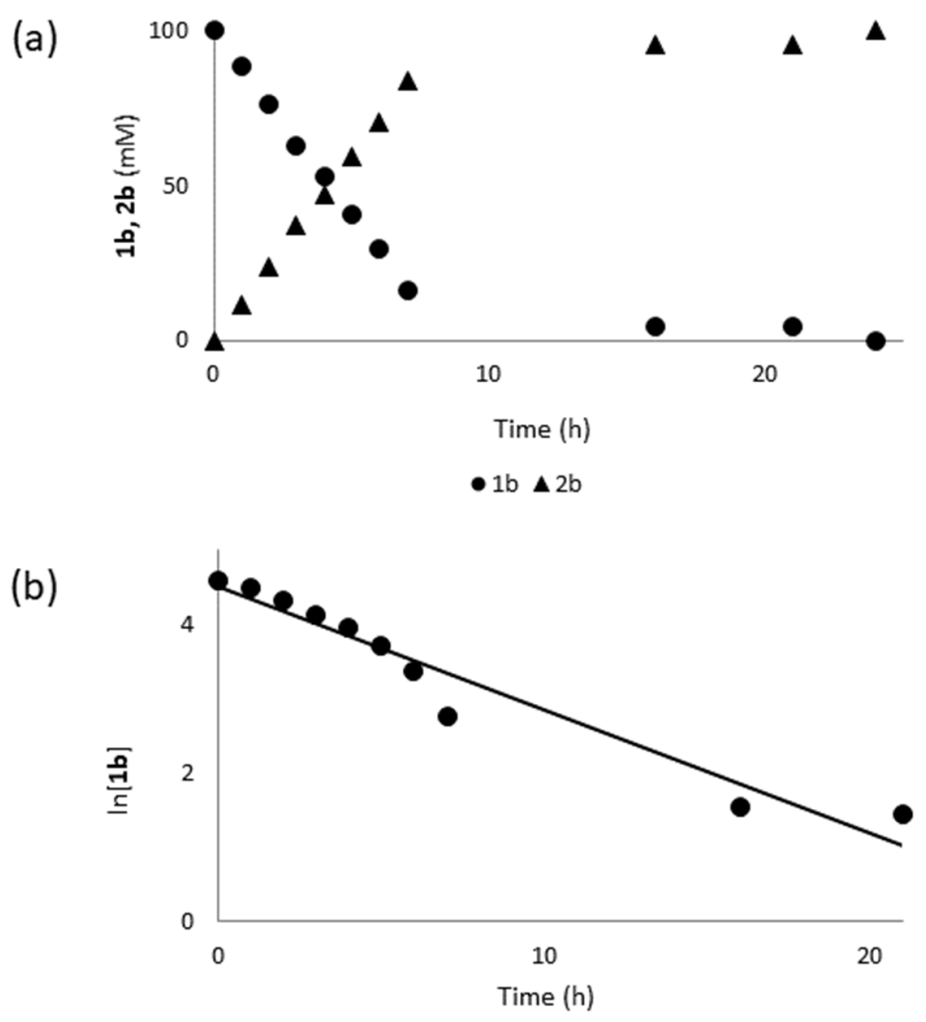

Figure 3: a) Cyclization of GlyAla (1) $\mathbf{b}$, circles) to cyclo(GlyAla) (2b, triangles) as a function of time b) First order decay fit of $\ln [\mathbf{1 b}]$ as a function of time. Conditions: $0.100 \mathrm{mmol} \mathbf{1 b}, 10.0 \mathrm{~mol} \% \mathrm{UiO}-66, \mathrm{MeOH}\left(0.10 \mathrm{~mol} \mathrm{~L}^{-1}\right), 80$ ${ }^{\circ} \mathrm{C} .{ }^{1} \mathrm{H}$ NMR yields.

Potential involvement of an ester intermediate. Motivated by the superiority of alcoholic solvents in our reactions, previous reports on the $\mathrm{UiO}-66 \mathrm{MOF}$ catalyzed esterification reactions under similar conditions, ${ }^{40}$ the formation of peptide bonds from ester substrates, ${ }^{74-75}$ and the facile cyclization of dipeptide esters to diketopiperazine products, ${ }^{73}$ we have probed the potential involvement of an intermediate ester in the reaction mechanism as depicted in Figure 2. To check whether intermediate formation of an ester and subsequent cyclization to the final products 1a,b could account for the superior reactivity observed in alcoholic solvents, we used GlyGly-OMe as a reaction substrate. After 3 h, GlyGly-OMe afforded 2a in $89 \%$ yield (Table S11), showing the feasibility of a potential intermediate ester cyclization. When the cyclization was blocked by protection of $1 \mathrm{a}$ N-terminal position with an acetyl group, the ester was formed in $\sim 80 \%$ of yield after $24 \mathrm{~h}$, indicating that ester formation may happen in these conditions (Table S12). However, little GlyGly-OMe ( 5\%) was detected through ${ }^{1} \mathrm{H}$ NMR and ESI-MS when the reaction of 1a 
was stopped before completion (Figure S16), suggesting that if ester is involved, its cyclization is likely not the rate determining step.

Computational study. Density Functional Theory (DFT) computations were also used to examine the mechanism of Zr-MOF catalyzed dipeptide cyclization, focusing on modelling of the reaction in ethanol solvent, given the identical results for reactions involving EtOH and $\mathrm{MeOH}$. Experimental characterization of UiO-66 structure revealed our system to be similar to previous reports (see SI for details), thus we based our computational model on a previous computational work on UiO-66. ${ }^{76-77}$ In this model, a representative cluster model of the MOF catalyst was chosen, comprising a single $\mathrm{Zr}_{6}$ core unit with one BDC linker defect and an ethoxy group as a defect-capping ligand (see SI for full computational details). Glycylglycine (1a) in its most stable canonical form in EtOH was used as a model substrate (Table S14).

At first, we compared the relative stability of different complexes formed from $\mathbf{1 a}$ and the $\mathrm{Zr}_{6}$ cluster, suggesting that the most stable form $\mathbf{A}$ involves 1a coordinating to a $\mathrm{Zr}$ center through its carboxylate group in monodentate fashion (Figure 4 and Figure S17). In A the carboxylic acid group in 1a is deprotonated and there is a neutral ethanol ligand at an adjacent $\mathrm{Zr}$ site. In general, other structures involving 1a monodentate binding to the free $\mathrm{Zr}$ site were found to be lower in energy for the deprotonated dipeptide than for its neutral form. In these complexes, the relative energy was found to vary as a function of the nature of the anchoring group within 1a that coordinates to the metal, in the order carboxylate group (most stable) < amide oxygen atom $<\mathrm{NH}_{2}$ group.

Using structure $\mathbf{A}$ as a reactant complex, we considered two potential reaction pathways, namely the formation of cyclic product 2a through a direct cyclization of 1a (Path A) or through the formation of an intermediate ester which cyclizes in situ (Path B) (Figure 2). The results suggest that an ester intermediate is not involved since the calculated barrier for its formation lies at $\sim 30 \mathrm{kcal} \mathrm{mol}^{-1}$ above complex $\mathbf{A}$, which is $c a .6 \mathrm{kcal} \mathrm{mol}^{-1}$ higher than the barrier for the direct cyclization. This is consistent with our experimental observations that the ester is present in small amounts, but can be formed in appreciable amounts if the cyclization is blocked through protection of the dipeptide's $\mathrm{NH}_{2}$ group. Therefore, reaction most likely proceeds through direct cyclization of $\mathbf{1 a}($ Path $A)$.

Proposed catalytic cycle. Considering the DFT results, which are in line with experiments, a reaction mechanism is proposed in Figure 4 (Figure S18). From complex A, sequential peptide bond trans/cis isomerization, $\mathrm{NH}_{2}$ attack, and water release steps take place to give the cyclized product $\mathbf{2 a}$ (Figure 4). The trans/cis isomerization transition state (TS) features a pyramidal $\mathrm{sp}^{3}$ geometry of the amide nitrogen atom, ${ }^{78-}$ ${ }^{80}$ which was computed to lie $23.1 \mathrm{kcal} \mathrm{mol}^{-1}$ above the reactant complex (A), and is consistent with 
experimental $\Delta G^{\ddagger}$ of $20.9 \mathrm{kcal} \mathrm{mol}^{-1}$ for amide isomerization under similar conditions. ${ }^{81}$ Moreover, our computed trans $/$ cis $\Delta G=2.8 \mathrm{kcal} \mathrm{mol}^{-1}$ matches the experimental value of $3.1 \mathrm{kcal} \mathrm{mol}^{-1}{ }^{81} \mathrm{Next}$, cis isomerized intermediate $\mathbf{B}$ undergoes several low barrier conformational changes that allow the $\mathrm{NH}_{2}$ group to move closer to the carboxylate group in preparation for the rate-determining nucleophilic addition, which generates cyclic tetrahedral intermediate $\mathbf{C}$. The TS for nucleophilic addition is predicted to lie $24.5 \mathrm{kcal}$ $\mathrm{mol}^{-1}$ above $\mathbf{A}$, in good agreement with the experimentally-derived $\Delta G^{\ddagger}$ of $27.2 \mathrm{kcal} \mathrm{mol}^{-1}$ (Figure 2 and Table S9). The $2.6 \mathrm{kcal} \mathrm{mol}^{-1}$ discrepancy is well within the estimated error bar of the protocol used here. In the last step, cyclic intermediate $\mathbf{C}$ releases water through a low-barrier proton shift from the $\mathrm{NH}_{2}$ to the $\mathrm{OH}$ group of the tetrahedral carbon. This transfer is assisted by the adjacent ethoxy group, whose absence would otherwise require formation of a highly-strained four-membered ring or the entropically disfavored involvement of an extra solvent molecule, resulting in higher energy barriers. ${ }^{82} \mathrm{Next}$, the formed water molecule is released, ultimately resulting in separate products, which are characterized by $\Delta \mathrm{G}=-14.2 \mathrm{kcal}$ $\mathrm{mol}^{-1}$ relative to the separate reactants (see SI for details).

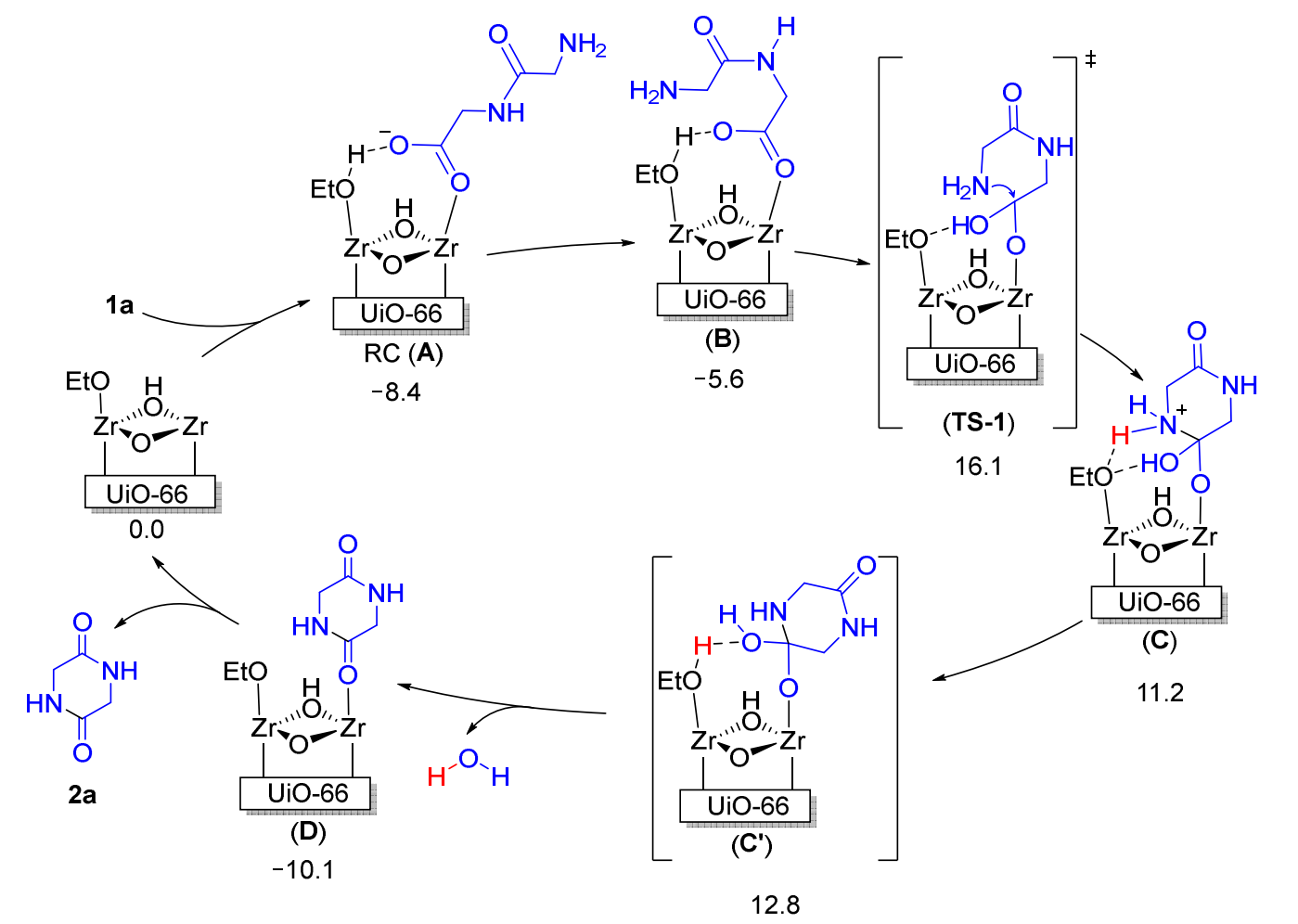

Figure 4: SMD-B3LYP-GD3BJ/BS2 relative free energies $\left(353.15 \mathrm{~K}, \mathrm{kcal} \mathrm{mol}^{-1}\right)$ for key intermediates and transition states along the computed intramolecular peptide bond formation reaction path (BS2 is a modified def2-TZVP basis set described in SI). 
Intermolecular peptide bond formation. The many benefits of $\mathrm{Zr}$-MOF catalysis for peptide bond formation outlined above prompted us to investigate whether intermolecular formation of peptide bonds could be achieved, as the MOF structure could favor the formation of this challenging amide bond. ${ }^{83}$ Accordingly, glycine (3a) and UiO-66 were incubated in $\mathrm{MeOH}$ at $80{ }^{\circ} \mathrm{C}$ (Table 3). After $24 \mathrm{~h}, 20 \%$ of glycine was quantitatively converted into a 1a:2a mixture ( 10:1 ratio) (Table 3, entry 1$)$. Using longer reaction times increased the yield, reaching an encouraging 75\% yield of a 1a:2a (1:2.6 ratio) mixture after $168 \mathrm{~h}$ (Table 3, entry 3). Increasing the temperature to $100{ }^{\circ} \mathrm{C}$ improved the $24 \mathrm{~h}$ reaction combined yield to only $50 \%$, and more of the cyclized product was observed (Table 3, entry 4). This sluggish reactivity prompted us to consider the removal of water from the system, as it is well known that the equilibrium can be driven to the peptide bond formation through water scavenging. ${ }^{84}$ However, using dry $\mathrm{MeOH}$ did not improve the yield (Table 3, entry 5), and combining dry $\mathrm{MeOH}$ with molecular sieves only improved the yield by $13 \%$ after $48 \mathrm{~h}$ (Table 3, entry 6 ). The apparent limited effect of molecular sieves in these reactions is puzzling, and contradicts the generally observed trend with many other catalysts reported in the literature. ${ }^{37}$ This could be related to the ability of Zr-MOFs to adsorb water, ${ }^{67}$ thereby acting both as a desiccant and a catalyst; however, this potential dual effect of the MOF structure in the intermolecular reaction would require further studies in order to be confirmed. Notably, negligible reactivity was observed with $\mathrm{Zr}\left({ }^{i} \mathrm{PrO}\right)_{4}$ under standard conditions $\left(80{ }^{\circ} \mathrm{C}\right.$, no molecular sieves), and only $46 \%$ of $\mathbf{1 a} / \mathbf{2 a}$ combined were produced in dry conditions $\left(100^{\circ} \mathrm{C}\right.$, with molecular sieves) after $48 \mathrm{~h}$. Further, no products were observed without MOF in the presence or absence of molecular sieves. Together, these results evidence the beneficial effect of the MOF network in enhancing the reactivity (Table S16). ${ }^{75}$

Table 3: Intermolecular peptide bond formation.

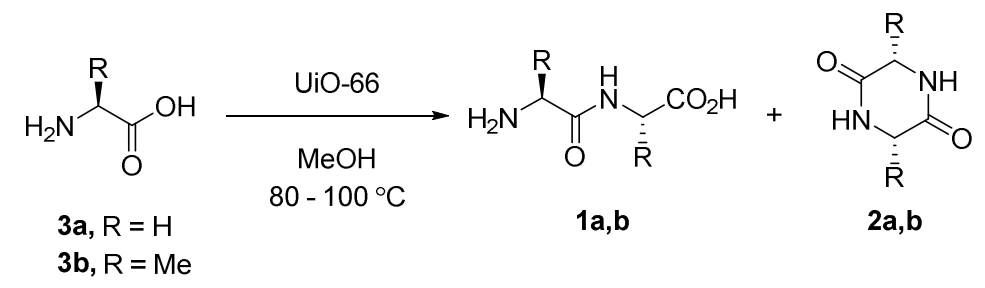

\begin{tabular}{cccccccc} 
Entry & $\mathbf{R}$ & $\mathbf{T}\left({ }^{\circ} \mathbf{C}\right)$ & Mol. Sieves? & Time $(\mathbf{h})$ & Conversion $(\%)$ & Yield 1+2 $(\%)$ & $\mathbf{1 : 2}$ \\
\hline 1 & H & 80 & --- & 24 & 20 & 20 & $10: 1$ \\
2 & H & 80 & --- & 96 & 39 & 39 & $1.2: 1$ \\
3 & H & 80 & --- & 168 & 75 & 75 & $1: 2.6$ \\
4 & H & 100 & --- & 24 & 50 & 50 & $1: 1.1$ \\
$5^{a}$ & H & 100 & --- & 24 & 50 & 50 & $1: 1.3$ \\
6 & H & 100 & Yes & 48 & 63 & 63 & $1: 7$
\end{tabular}




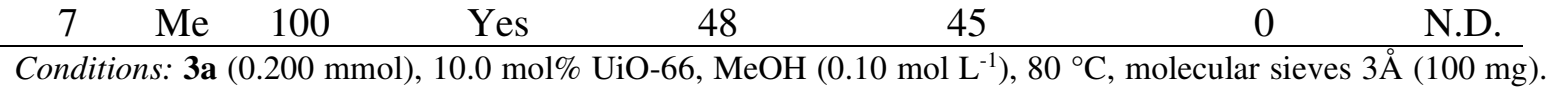

${ }^{1} \mathrm{H}$ NMR yields. ${ }^{a}$ Dry MeOH.

The counterintuitive selectivity favoring $\mathbf{1}$ at shorter reaction times motivated us to investigate the mechanism of this reaction by DFT modelling of the key intermediates and transition states along the reaction path, as shown in Figure 4 (see SI for more details). Our calculations estimated the energy barrier for the intermolecular reaction to be $\sim 4 \mathrm{kcal} \mathrm{mol}^{-1}$ higher relative to the '3a-free' intramolecular peptide bond formation, which is in qualitative agreement with the longer reaction times and selectivity observed for intermolecular reaction (Table 3 vs. Tables 1 and 2), as well as the non observation of triglycine or longer oligomers. However, the observed 1a:2a ratios obtained at early stages of the reaction together with similar binding energies of glycine and 1a to UiO-66 suggest that 3a might inhibit the cyclization (Figure 5). This inhibition was confirmed by adding 3a to a standard GlyAla (1b) cyclization (17\% yield vs. 100\% yield in absence of 3a, Table S18).

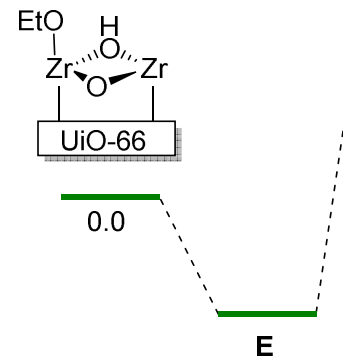

$-9.1$

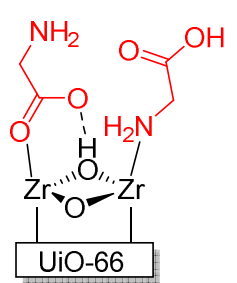

E
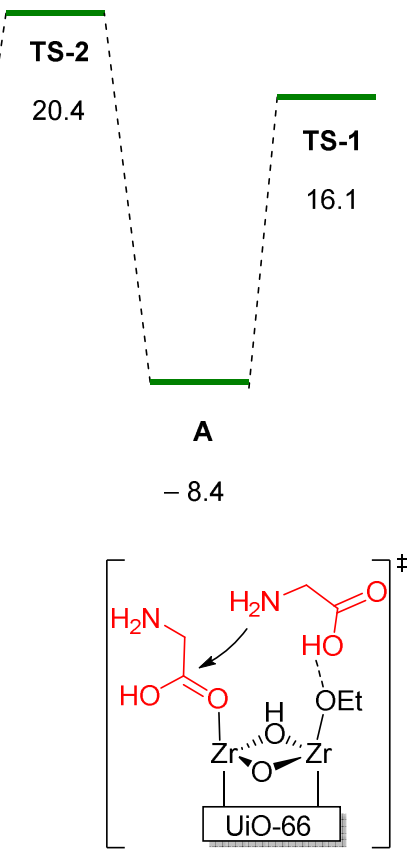

TS-2

Figure 5: SMD-B3LYP-GD3BJ/BS2 relative free energies $\left(353.15 \mathrm{~K}, \mathrm{kcal} \mathrm{mol}^{-1}\right)$ for key intermediates and transition states along the computed intermolecular peptide bond formation reaction path (BS2 is a modified def2-TZVP basis set described in SI). 
Attempts to extend the intermolecular reaction to other amino acids was not successful. A dimerization of alanine under the same conditions used for glycine failed to provide desired adducts (Table 3, entry 7). Attempts to optimize reaction concentration, temperature, and the presence or absence of molecular sieves were unfortunately not fruitful. In several cases, part of the initial alanine was not recovered, which was attributed primarily to its adsorption. However, aromatic signals coherent with a para substituted aromatic ring could be detected in the NMR of crude reaction mixtures, suggesting that the MOF linker reacts preferably with the amino acid substrates bulkier than glycine. Though we were not able to identify the product formed, loss of MOF network structure due to esterification of linkers has been reported before. ${ }^{85}$ However, PXRD analysis after the reaction showed the overall structure of MOF remains intact, suggesting that the lack of reactivity could not be due to the MOF decomposition. Further attempts to facilitate the intermolecular peptide coupling led us to react H-Gly-OMe with different amino acids. However, in these reactions only cGG was observed, and dimerization of H-Ala-OMe also did not afford the linear or cyclic product (Table S17).

This unexpected lack of reactivity with other amino acids led us to probe more conventional organic substrates such as phenylacetic acid and benzylamine under the same conditions (Table 4). The $\mathrm{N}$-benzyl2-phenylacetamide 6 product was observed in low yields even in the presence of molecular sieves (entries 1 and 2). Preliminary optimization could elevate the yield up to $88 \%$ by exchanging the reaction solvent to dioxane, and using molecular sieves, whose effect in this case is in line with prior reports (entries 3-6). ${ }^{6,86-}$ ${ }^{88}$ These results show that the extent to which water removal affects the reaction depends on the substrate and/or reaction condition being used, and that even currently available Zr-MOFs might need water removal techniques to provide good yields after all. However, given that $\mathbf{6}$ was formed, the lack of reactivity observed with amino acids other than glycine suggests that it is rather the catalyst structure, and not the reaction itself or a poor water removal, that is precluding product formation. In this sense, the overall optimization of the Zr-MOF structure would be needed in order to make the catalytic activity more general toward intermolecular reactions. 
Table 4: UiO-66 catalyzes intermolecular amide bond formation.

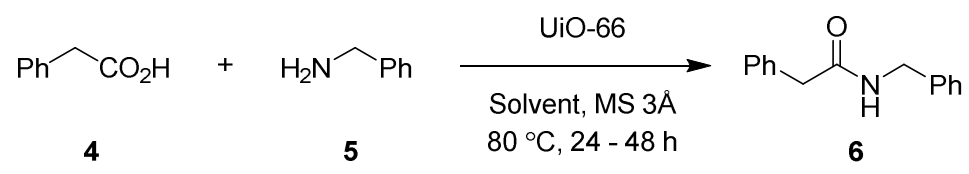

\begin{tabular}{|c|c|c|c|c|}
\hline Entry & Solvent & Mol. Sieves? & Time (h) & Yield $6(\%)$ \\
\hline 1 & $\mathrm{EtOH}$ & No & 24 & 14 \\
\hline $2^{a}$ & $\mathrm{EtOH}$ & Yes & 24 & 18 \\
\hline 3 & 1,4-dioxane & No & 24 & 39 \\
\hline 4 & 1,4-dioxane & No & 71 & 41 \\
\hline 5 & 1,4-dioxane & Yes & 71 & 88 \\
\hline $6^{a}$ & 1,4-dioxane & Yes & 24 & $84\left(75^{b}\right)$ \\
\hline $7^{a, c}$ & 1,4-dioxane & Yes & 24 & 16 \\
\hline
\end{tabular}

Overall, these explorative results for the direct dimerization of unprotected commercially available amino acids showcases the potential of Zr-MOFs in streamlining the intermolecular catalytic peptide bond formation, although further optimization of the MOF catalyst structure is clearly necessary to expand the reaction scope to a broader range of amino acids.

\section{Conclusion}

In conclusion, we discovered the high-potential of $\mathrm{Zr}-\mathrm{MOFs}$ as a new class of heterogeneous catalysts for peptide bond formation. We have shown that UiO-66 efficiently catalyzes the intramolecular formation of peptide bonds directly from free amines and non-activated carboxylic acids without any additives, drying agents, inert atmosphere or special protocols to remove water from the reaction. Good yields were obtained for a variety of substrates containing Lewis basic functional groups and bulky side chains, including a secondary amine group. Remarkably, UiO-66 is stable under the reaction conditions and shows a water tolerance that largely superseded other $\mathrm{Zr}$ (IV) catalysts, resulting in a straightforward recycling of the catalyst and showcasing the potential of Zr-MOFs as viable sustainable and water-tolerant catalysts for the amide bond formation. In addition, our detailed mechanistic investigation uncovered several important features for the design of future catalysts, such as 1) the interplay between MOF structure, reaction solvent and the easy recovery of substrates and products, which might have a significant impact on the overall process efficiency, 2) the key role of an alkoxy group on the adjacent metal center in lowering the barrier 
of key proton transfers and 3) the non-involvement of an ester intermediate, indicating a more general reaction scope is feasible for Zr-MOFs. Finally, we provide proof-of-concept that a similar mechanism also enables the formation of intermolecular peptide bonds directly from unprotected commercially available glycine. Even though further catalyst structure optimization is needed to expand this reactivity to other amino acids precursors, these results underline a high catalytic potential of Zr-MOFs that can impact a broad range of scientific areas.

\section{AUTHOR INFORMATION}

$¥$ These authors contributed equally to this work.

Corresponding Author *E-mail: tatjana.vogt@kuleuven.be

\section{Orcid}

Tatjana N. Parac-Vogt: 0000-0002-6188-3957

Francisco de Azambuja: 0000-0002-5537-5411

Dragan Conic: 0000-0002-6251-7254

Notes The authors declare no competing financial interest.

\section{ASSOCIATED CONTENT}

Supporting Information. Experimental procedures, supplementary experiments, copy of NMR spectra (PDF), computational study details and results, 'xyz' coordinates of UiO-66 starting cluster model. This information is available free of charge on the ACS Publications website.

\section{ACKNOWLEDGMENTS}

We thank KU Leuven and Research Foundation Flanders (FWO) for financial support. F.d.A $(195931 / 1281921 N)$ and A.L. (48730/1S10318N) thank the FWO for fellowships. 


\section{REFERENCES}

1. Sabatini, M. T.; Boulton, L. T.; Sneddon, H. F.; Sheppard, T. D. A Green Chemistry Perspective on Catalytic Amide Bond Formation. Nat. Catal. 2019, 2, 10-17. https://doi.org/10.1038/s41929-018-0211-5

2. Wang, X. Challenges and Outlook for Catalytic Direct Amidation Reactions. Nat. Catal. 2019, 2, 98-102. https://doi.org/10.1038/s41929-018-0215-1

3. Dunetz, J. R.; Magano, J.; Weisenburger, G. A. Large-Scale Applications of Amide Coupling Reagents for the Synthesis of Pharmaceuticals. Org. Process Res. Dev. 2016, 20, 140-177. https://doi.org/10.1021/op500305s

4. $\quad$ Isidro-Llobet, A.; Kenworthy, M. N.; Mukherjee, S.; Kopach, M. E.; Wegner, K.; Gallou, F.; Smith, A. G.; Roschangar, F. Sustainability Challenges in Peptide Synthesis and Purification: From R\&D to Production. J. Org. Chem. 2019, 84, 4615-4628. https://doi.org/10.1021/acs.joc.8b03001

5. $\quad$ Sabatini, M. T.; Karaluka, V.; Lanigan, R. M.; Boulton, L. T.; Badland, M.; Sheppard, T. D. ProtectingGroup-Free Amidation of Amino Acids using Lewis Acid Catalysts. Chem. Eur. J. 2018, 24, 7033-7043. https://doi.org/10.1002/chem.201800372

6. Lundberg, H.; Adolfsson, H. Hafnium-Catalyzed Direct Amide Formation at Room Temperature. ACS Catal. 2015, 5, 3271-3277. https://doi.org/10.1021/acscatal.5b00385

7. Tsuji, H.; Yamamoto, H. Hydroxy-Directed Amidation of Carboxylic Acid Esters Using a Tantalum Alkoxide Catalyst. J. Am. Chem. Soc. 2016, 138, 14218-14221. https://doi.org/10.1021/jacs.6b09482

8. Li, N.; Wang, L.; Zhang, L.; Zhao, W.; Qiao, J.; Xu, X.; Liang, Z. Air-stable Bis(pentamethylcyclopentadienyl) Zirconium Perfluorooctanesulfonate as an Efficient and Recyclable Catalyst for the Synthesis of N-substituted Amides. ChemCatChem 2018, 10, 3532-3538. https://doi.org/10.1002/cctc.201800590

9. Lundberg, H.; Tinnis, F.; Adolfsson, H. Zirconium catalyzed amide formation without water scavenging. Appl. Organomet. Chem. 2019, 33, e5062. https://doi.org/10.1002/aoc.5062

10. Lundberg, H.; Tinnis, F.; Selander, N.; Adolfsson, H. Catalytic Amide Formation from Non-Activated Carboxylic Acids and Amines. Chem. Soc. Rev. 2014, 43, 2714-2742. http://dx.doi.org/10.1039/C3CS60345H

11. Noda, H.; Furutachi, M.; Asada, Y.; Shibasaki, M.; Kumagai, N. Unique Physicochemical and Catalytic Properties Dictated by the $\mathrm{B}_{3} \mathrm{NO}_{2}$ Ring System. Nat. Chem. 2017, 9, 571. https://doi.org/10.1038/nchem. 2708

12. Sabatini, M. T.; Boulton, L. T.; Sheppard, T. D. Borate Esters: Simple Catalysts for the Sustainable Synthesis of Complex Amides. Science Advances 2017, 3, e1701028. https://advances.sciencemag.org/content/advances/3/9/e1701028.full.pdf

13. Michigami, K.; Sakaguchi, T.; Takemoto, Y. Catalytic Dehydrative Peptide Synthesis with gem-Diboronic Acids. ACS Catal. 2020, 10, 683-688. https://doi.org/10.1021/acscatal.9b03894

14. Muramatsu, W.; Tsuji, H.; Yamamoto, H. Catalytic Peptide Synthesis: Amidation of N-Hydroxyimino Esters. ACS Catal. 2018, 8, 2181-2187. https://doi.org/10.1021/acscatal.7b04244

15. Muramatsu, W.; Yamamoto, H. Tantalum-Catalyzed Amidation of Amino Acid Homologues. J. Am. Chem. Soc. 2019, 141, 18926-18931. https://doi.org/10.1021/jacs.9b08415

16. Handoko; Satishkumar, S.; Panigrahi, N. R.; Arora, P. S. Rational Design of an Organocatalyst for Peptide Bond Formation. J. Am. Chem. Soc. 2019, 141, 15977-15985. https://doi.org/10.1021/jacs.9b07742 
17. de Azambuja, F.; Parac-Vogt, T. N. Water-Tolerant and Atom Economical Amide Bond Formation by MetalSubstituted Polyoxometalate Catalysts. ACS Catal. 2019, 9, 10245-10252. https://doi.org/10.1021/acscatal.9b03415

18. de Azambuja, F.; Lenie, J.; Parac-Vogt, T. N. Homogeneous Metal Catalysts with Inorganic Ligands: Probing Ligand Effects in Lewis Acid Catalyzed Direct Amide Bond Formation. ACS Catal. 2021, 11, 271-277. https://doi.org/10.1021/acscatal.0c04189

19. Calcio Gaudino, E.; Carnaroglio, D.; Nunes, M. A. G.; Schmidt, L.; Flores, E. M. M.; Deiana, C.; Sakhno, Y.; Martra, G.; Cravotto, G. Fast TiO2-catalyzed direct amidation of neat carboxylic acids under mild dielectric heating. Catal. Sci. Technol. 2014, 4, 1395-1399. http://dx.doi.org/10.1039/C4CY00038B

20. Gu, L.; Lim, J.; Cheong, J. L.; Lee, S. S. MCF-supported boronic acids as efficient catalysts for direct amide condensation of carboxylic acids and amines. Chem. Commun. 2014, 50, 7017-7019. http://dx.doi.org/10.1039/C4CC01148A

21. Ali, M. A.; Siddiki, S. M. A. H.; Onodera, W.; Kon, K.; Shimizu, K.-i. Amidation of Carboxylic Acids with Amines by $\mathrm{Nb2O} 5$ as a Reusable Lewis Acid Catalyst. ChemCatChem 2015, 7, 3555-3561. https://doi.org/10.1002/cctc.201500672

22. Zakharova, M. V.; Kleitz, F.; Fontaine, F.-G. Lewis acidity quantification and catalytic activity of Ti, Zr and Al-supported mesoporous silica. Dalton Trans. 2017, 46, 3864-3876. http://dx.doi.org/10.1039/C7DT00035A

23. Deiana, C.; Sakhno, Y.; Fabbiani, M.; Pazzi, M.; Vincenti, M.; Martra, G. Direct Synthesis of Amides from Carboxylic Acids and Amines by Using Heterogeneous Catalysts: Evidence of Surface Carboxylates as Activated Electrophilic Species. ChemCatChem 2013, 5, 2832-2834. https://doi.org/10.1002/cctc.201300164

24. Arena, F.; Deiana, C.; Lombardo, A. F.; Ivanchenko, P.; Sakhno, Y.; Trunfio, G.; Martra, G. Activity patterns of metal oxide catalysts in the synthesis of N-phenylpropionamide from propanoic acid and aniline. Catal. Sci. Technol. 2015, 5, 1911-1918. http://dx.doi.org/10.1039/C4CY01504E

25. Siddiki, S. M. A. H.; Rashed, M. N.; Ali, M. A.; Toyao, T.; Hirunsit, P.; Ehara, M.; Shimizu, K.-i. Lewis Acid Catalysis of Nb2O5 for Reactions of Carboxylic Acid Derivatives in the Presence of Basic Inhibitors. ChemCatChem 2019, 11, 383-396. https://doi.org/10.1002/cctc.201801239

26. Samantaray, M. K.; Pump, E.; Bendjeriou-Sedjerari, A.; D’Elia, V.; Pelletier, J. D. A.; Guidotti, M.; Psaro, R.; Basset, J.-M. Surface organometallic chemistry in heterogeneous catalysis. Chem. Soc. Rev. 2018, 47, 8403-8437. http://dx.doi.org/10.1039/C8CS00356D

27. Samantaray, M. K.; D’Elia, V.; Pump, E.; Falivene, L.; Harb, M.; Ould Chikh, S.; Cavallo, L.; Basset, J.-M. The Comparison between Single Atom Catalysis and Surface Organometallic Catalysis. Chem. Rev. 2020, 120, $734-$ 813. https://doi.org/10.1021/acs.chemrev.9b00238

28. Corma, A.; García, H.; Llabrés i Xamena, F. X. Engineering Metal Organic Frameworks for Heterogeneous Catalysis. Chem. Rev. 2010, 110, 4606-4655. https://doi.org/10.1021/cr9003924

29. Dhakshinamoorthy, A.; Li, Z.; Garcia, H. Catalysis and photocatalysis by metal organic frameworks. Chem. Soc. Rev. 2018, 47, 8134-8172. http://dx.doi.org/10.1039/C8CS00256H

30. Pascanu, V.; González Miera, G.; Inge, A. K.; Martín-Matute, B. Metal-Organic Frameworks as Catalysts for Organic Synthesis: A Critical Perspective. J. Am. Chem. Soc. 2019, 141, 7223-7234. https://doi.org/10.1021/jacs.9b00733

31. Yang, D.; Gates, B. C. Catalysis by Metal Organic Frameworks: Perspective and Suggestions for Future Research. ACS Catal. 2019, 9, 1779-1798. https://doi.org/10.1021/acscatal.8b04515 
32. Bavykina, A.; Kolobov, N.; Khan, I. S.; Bau, J. A.; Ramirez, A.; Gascon, J. Metal-Organic Frameworks in Heterogeneous Catalysis: Recent Progress, New Trends, and Future Perspectives. Chem. Rev. 2020, 120, 8468-8535. https://doi.org/10.1021/acs.chemrev.9b00685

33. Diercks, C. S.; Kalmutzki, M. J.; Diercks, N. J.; Yaghi, O. M. Conceptual Advances from Werner Complexes to Metal-Organic Frameworks. ACS Cent. Sci. 2018, 4, 1457-1464. https://doi.org/10.1021/acscentsci.8b00677

34. Fang, Z.; Bueken, B.; De Vos, D. E.; Fischer, R. A. Defect-Engineered Metal-Organic Frameworks. Angew. Chem. Int. Ed. 2015, 54, 7234-7254. https://onlinelibrary.wiley.com/doi/abs/10.1002/anie.201411540

35. DeStefano, M. R.; Islamoglu, T.; Garibay, S. J.; Hupp, J. T.; Farha, O. K. Room-Temperature Synthesis of UiO-66 and Thermal Modulation of Densities of Defect Sites. Chem. Mater. 2017, 29, 1357-1361. https://doi.org/10.1021/acs.chemmater.6b05115

36. Feng, X.; Hajek, J.; Jena, H. S.; Wang, G.; Veerapandian, S. K. P.; Morent, R.; De Geyter, N.; Leyssens, K.; Hoffman, A. E. J.; Meynen, V.; Marquez, C.; De Vos, D. E.; Van Speybroeck, V.; Leus, K.; Van Der Voort, P. Engineering a Highly Defective Stable UiO-66 with Tunable Lewis- Brønsted Acidity: The Role of the Hemilabile Linker. J. Am. Chem. Soc. 2020, 142, 3174-3183. https://doi.org/10.1021/jacs.9b13070

37. Todorovic, M.; Perrin, D. M. Recent developments in catalytic amide bond formation. Peptide Science 2020, 112, e24210. https://doi.org/10.1002/pep2.24210

38. Cirujano, F. G.; Corma, A.; Llabrés i Xamena, F. X. Conversion of levulinic acid into chemicals: Synthesis of biomass derived levulinate esters over Zr-containing MOFs. Chem. Eng. Sci. 2015, 124, 52-60. http://www.sciencedirect.com/science/article/pii/S000925091400551X

39. Cirujano, F. G.; Corma, A.; Llabrés i Xamena, F. X. Zirconium-containing metal organic frameworks as solid acid catalysts for the esterification of free fatty acids: Synthesis of biodiesel and other compounds of interest. Catal. Today 2015, 257, 213-220. http://www.sciencedirect.com/science/article/pii/S0920586114005926

40. Caratelli, C.; Hajek, J.; Cirujano, F. G.; Waroquier, M.; Llabrés i Xamena, F. X.; Van Speybroeck, V. Nature of active sites on UiO-66 and beneficial influence of water in the catalysis of Fischer esterification. J. Catal. 2017, 352, 401-414. http://www.sciencedirect.com/science/article/pii/S002195171730221X

41. Wang, F.; Chen, Z.; Chen, H.; Goetjen, T. A.; Li, P.; Wang, X.; Alayoglu, S.; Ma, K.; Chen, Y.; Wang, T.; Islamoglu, T.; Fang, Y.; Snurr, R. Q.; Farha, O. K. Interplay of Lewis and Brønsted Acid Sites in Zr-Based MetalOrganic Frameworks for Efficient Esterification of Biomass-Derived Levulinic Acid. ACS Appl. Mater. Interfaces 2019, 11, 32090-32096. https://doi.org/10.1021/acsami.9b07769

42. Villoria-del-Álamo, B.; Rojas-Buzo, S.; García-García, P.; Corma, A. Zr-MOF-808 as Catalyst for Amide Esterification. Chem. Eur. J. 2020, n/a. https://doi.org/10.1002/chem.202003752

43. Hoang, L. T. M.; Ngo, L. H.; Nguyen, H. L.; Nguyen, H. T. H.; Nguyen, C. K.; Nguyen, B. T.; Ton, Q. T.; Nguyen, H. K. D.; Cordova, K. E.; Truong, T. An azobenzene-containing metal-organic framework as an efficient heterogeneous catalyst for direct amidation of benzoic acids: synthesis of bioactive compounds. Chem. Commun. 2015, 51, 17132-17135. http://dx.doi.org/10.1039/C5CC05985B

44. $\quad$ Moons, J.; de Azambuja, F.; Mihailovic, J.; Kozma, K.; Smiljanic, K.; Amiri, M.; Cirkovic Velickovic, T.; Nyman, M.; Parac-Vogt, T. N. Discrete $\mathrm{Hf}_{18}$ Metal-oxo Cluster as a Heterogeneous Nanozyme for Site-Specific Proteolysis. Angew. Chem. Int. Ed. 2020, 59, 9094-9101. https://doi.org/10.1002/anie.202001036

45. de Azambuja, F.; Moons, J.; Parac-Vogt, T. N. The Dawn of Metal-Oxo Clusters as Artificial Proteases: From Discovery to the Present and Beyond. Acc. Chem. Res. 2021, 54, 1673-1684. https://doi.org/10.1021/acs.accounts.0c00666 
46. Ly, H. G. T.; Fu, G.; Kondinski, A.; Bueken, B.; De Vos, D.; Parac-Vogt, T. N. Superactivity of MOF-808 toward Peptide Bond Hydrolysis. J. Am. Chem. Soc. 2018, 140, 6325-6335. https://doi.org/10.1021/jacs.8b01902

47. Conic, D.; Pierloot, K.; Parac-Vogt, T. N.; Harvey, J. N. Mechanism of the highly effective peptide bond hydrolysis by MOF-808 catalyst under biologically relevant conditions. PCCP 2020, 22, 25136-25145. http://dx.doi.org/10.1039/D0CP04775A

48. Loosen, A.; de Azambuja, F.; Smolders, S.; Moons, J.; Simms, C.; De Vos, D.; Parac-Vogt, T. N. Interplay between structural parameters and reactivity of $\mathrm{Zr}_{6}$-based MOFs as artificial proteases. Chem. Sci. 2020, 11, 66626669. http://dx.doi.org/10.1039/D0SC02136A

49. Ly, H. G. T.; Fu, G.; de Azambuja, F.; De Vos, D. E.; Parac-Vogt, T. N. Nanozymatic Activity of UiO-66 Metal-Organic Frameworks: Tuning the Nanopore Environment Enhances Hydrolytic Activity toward Peptide Bonds. ACS Appl. Nano Mater. 2020, 3, 8931-8938. https://doi.org/10.1021/acsanm.0c01688

50. James Cleaves Ii, H.; Michalkova Scott, A.; Hill, F. C.; Leszczynski, J.; Sahai, N.; Hazen, R. Mineral-organic interfacial processes: potential roles in the origins of life. Chem. Soc. Rev. 2012, 41, 5502-5525. http://dx.doi.org/10.1039/C2CS35112A

51. Kitadai, N.; Nishiuchi, K. Thermodynamic Impact of Mineral Surfaces on Amino Acid Polymerization: Aspartate Dimerization on Goethite. Astrobiology 2019, $19, \quad$ 1363-1376. https://www.liebertpub.com/doi/abs/10.1089/ast.2018.1967

52. Rimola, A.; Sodupe, M.; Ugliengo, P. Role of Mineral Surfaces in Prebiotic Chemical Evolution. In Silico Quantum Mechanical Studies. Life 2019, 9, 10. https://www.mdpi.com/2075-1729/9/1/10

53. Sakhno, Y.; Battistella, A.; Mezzetti, A.; Jaber, M.; Georgelin, T.; Michot, L.; Lambert, J.-F. One Step up the Ladder of Prebiotic Complexity: Formation of Nonrandom Linear Polypeptides from Binary Systems of Amino Acids on Silica. Chem. Eur. J. 2019, 25, 1275-1285. https://doi.org/10.1002/chem.201803845

54. de Castro Silva, F.; Lima, L. C. B.; Silva-Filho, E. C.; Fonseca, M. G.; Lambert, J.-F.; Jaber, M. A comparative study of alanine adsorption and condensation to peptides in two clay minerals. Applied Clay Science 2020, 192, 105617. https://www.sciencedirect.com/science/article/pii/S0169131720301824

55. Rimola, A.; Costa, D.; Sodupe, M.; Lambert, J.-F.; Ugliengo, P. Silica Surface Features and Their Role in the Adsorption of Biomolecules: Computational Modeling and Experiments. Chem. Rev. 2013, 113, 4216-4313. https://doi.org/10.1021/cr3003054

56. Martra, G.; Deiana, C.; Sakhno, Y.; Barberis, I.; Fabbiani, M.; Pazzi, M.; Vincenti, M. The Formation and Self-Assembly of Long Prebiotic Oligomers Produced by the Condensation of Unactivated Amino Acids on Oxide Surfaces. Angew. Chem. Int. Ed. 2014, 53, 4671-4674. https://doi.org/10.1002/anie.201311089

57. Rimola, A.; Fabbiani, M.; Sodupe, M.; Ugliengo, P.; Martra, G. How Does Silica Catalyze the Amide Bond Formation under Dry Conditions? Role of Specific Surface Silanol Pairs. ACS Catal. 2018, 8, 4558-4568. https://doi.org/10.1021/acscatal.7b03961

58. Guo, C.; Jordan, J. S.; Yarger, J. L.; Holland, G. P. Highly Efficient Fumed Silica Nanoparticles for Peptide Bond Formation: Converting Alanine to Alanine Anhydride. ACS Appl. Mater. Interfaces 2017, 9, 17653-17661. https://doi.org/10.1021/acsami.7b04887

59. Howarth, A. J.; Liu, Y.; Li, P.; Li, Z.; Wang, T. C.; Hupp, J. T.; Farha, O. K. Chemical, thermal and mechanical stabilities of metal-organic frameworks. Nat. Rev. Mater. 2016, 1, 1-15. 
60. Cavka, J. H.; Jakobsen, S.; Olsbye, U.; Guillou, N.; Lamberti, C.; Bordiga, S.; Lillerud, K. P. A new zirconium inorganic building brick forming metal organic frameworks with exceptional stability. J. Am. Chem. Soc. 2008, 130, 13850-13851.

61. Rimoldi, M.; Howarth, A. J.; DeStefano, M. R.; Lin, L.; Goswami, S.; Li, P.; Hupp, J. T.; Farha, O. K. Catalytic Zirconium/Hafnium-Based Metal-Organic Frameworks. ACS Catal. 2017, 7, 997-1014. https://doi.org/10.1021/acscatal.6b02923

62. Reinsch, H.; Waitschat, S.; Chavan, S. M.; Lillerud, K. P.; Stock, N. A facile "green" route for scalable batch production and continuous synthesis of zirconium MOFs. Eur. J. Inorg. Chem. 2016, 2016, 4490-4498.

63. Wang, T. C.; Vermeulen, N. A.; Kim, I. S.; Martinson, A. B.; Stoddart, J. F.; Hupp, J. T.; Farha, O. K. Scalable synthesis and post-modification of a mesoporous metal-organic framework called NU-1000. Nat. Protoc. 2016, 11, 149-62. https://www.ncbi.nlm.nih.gov/pubmed/26678084

64. Katz, M. J.; Brown, Z. J.; Colón, Y. J.; Siu, P. W.; Scheidt, K. A.; Snurr, R. Q.; Hupp, J. T.; Farha, O. K. A facile synthesis of UiO-66, UiO-67 and their derivatives. ChemComm 2013, 49, 9449-9451.

65. Pan, L.; Heddy, R.; Li, J.; Zheng, C.; Huang, X.-Y.; Tang, X.; Kilpatrick, L. Synthesis and Structural Determination of a Hexanuclear Zirconium Glycine Compound Formed in Aqueous Solution. Inorg. Chem. 2008, 47, 5537-5539. https://doi.org/10.1021/ic800292e

66. Kickelbick, G.; Feth, M. P.; Bertagnolli, H.; Puchberger, M.; Holzinger, D.; Gross, S. Formation of organically surface-modified metal oxo clusters from carboxylic acids and metal alkoxides: a mechanistic study. $J$. Chem. Soc., Dalton Trans. 2002, 3892-3898. http://dx.doi.org/10.1039/B207994A

67. Liu, X.; Wang, X.; Kapteijn, F. Water and Metal-Organic Frameworks: From Interaction toward Utilization. Chem. Rev. 2020, 120, 8303-8377. https://doi.org/10.1021/acs.chemrev.9b00746

68. Kobayashi, S.; Nagayama, S.; Busujima, T. Lewis Acid Catalysts Stable in Water. Correlation between Catalytic Activity in Water and Hydrolysis Constants and Exchange Rate Constants for Substitution of Inner-Sphere Water Ligands. J. Am. Chem. Soc. 1998, 120, 8287-8288. https://doi.org/10.1021/ja980715q

69. Zhang, Y.; de Azambuja, F.; Parac-Vogt, T. N. The forgotten chemistry of group(IV) metals: A survey on the synthesis, structure, and properties of discrete $\mathrm{Zr}(\mathrm{IV}), \mathrm{Hf}(\mathrm{IV})$, and Ti(IV) oxo clusters. Coord. Chem. Rev. 2021, 438, 213886. https://www.sciencedirect.com/science/article/pii/S001085452100120X

70. Mihaylov, T. T.; Ly, H. G. T.; Pierloot, K.; Parac-Vogt, T. N. Molecular Insight from DFT Computations and Kinetic Measurements into the Steric Factors Influencing Peptide Bond Hydrolysis Catalyzed by a Dimeric $\mathrm{Zr}(\mathrm{IV})-$ Substituted Keggin Type Polyoxometalate. Inorg. Chem. 2016, 55, 9316-9328. https://doi.org/10.1021/acs.inorgchem.6b01461

71. Lundberg, H.; Tinnis, F.; Zhang, J.; Algarra, A. G.; Himo, F.; Adolfsson, H. Mechanistic Elucidation of Zirconium-Catalyzed Direct Amidation. J. Am. Chem. Soc. 2017, 139, 2286-2295. https://doi.org/10.1021/jacs.6b10973

72. Caratelli, C.; Hajek, J.; Rogge, S. M. J.; Vandenbrande, S.; Meijer, E. J.; Waroquier, M.; Van Speybroeck, V. Influence of a Confined Methanol Solvent on the Reactivity of Active Sites in UiO-66. ChemPhysChem 2018, 19, 420-429. https://doi.org/10.1002/cphc.201701109

73. Tullberg, M.; Grøtli, M.; Luthman, K. Efficient synthesis of 2,5-diketopiperazines using microwave assisted heating. Tetrahedron 2006, 62, 7484-7491. http://www.sciencedirect.com/science/article/pii/S0040402006007563 
74. Forsythe, J. G.; Yu, S.-S.; Mamajanov, I.; Grover, M. A.; Krishnamurthy, R.; Fernández, F. M.; Hud, N. V. Ester-Mediated Amide Bond Formation Driven by Wet-Dry Cycles: A Possible Path to Polypeptides on the Prebiotic Earth. Angew. Chem. Int. Ed. 2015, 54, 9871-9875. https://doi.org/10.1002/anie.201503792

75. Schapp, J.; Beck, W. Metal complexes of biologically important ligands. Part CXLVIII. Synthesis of peptides from glycine ester catalyzed by triflates and chlorides of metal(III, IV and VI) ions. Z. Naturforsch., B: Chem. Sci. 2003, 58, 85-91. https://doi.org/10.1515/znb-2003-0111

76. Yang, D.; Bernales, V.; Islamoglu, T.; Farha, O. K.; Hupp, J. T.; Cramer, C. J.; Gagliardi, L.; Gates, B. C. Tuning the Surface Chemistry of Metal Organic Framework Nodes: Proton Topology of the Metal-Oxide-Like $\mathrm{Zr}_{6}$ Nodes of UiO-66 and NU-1000. J. Am. Chem. Soc. 2016, 138, 15189-15196. https://doi.org/10.1021/jacs.6b08273

77. Yang, D.; Ortuño, M. A.; Bernales, V.; Cramer, C. J.; Gagliardi, L.; Gates, B. C. Structure and Dynamics of $\mathrm{Zr}_{6} \mathrm{O}_{8}$ Metal-Organic Framework Node Surfaces Probed with Ethanol Dehydration as a Catalytic Test Reaction. $J$. Am. Chem. Soc. 2018, 140, 3751-3759. https://doi.org/10.1021/jacs.7b13330

78. Mantz, Y. A.; Gerard, H.; Iftimie, R.; Martyna, G. J. Isomerization of a Peptidic Fragment Studied Theoretically in Vacuum and in Explicit Water Solvent at Finite Temperature. J. Am. Chem. Soc. 2004, 126, 40804081. https://doi.org/10.1021/ja030512o

79. Mantz, Y. A.; Gerard, H.; Iftimie, R.; Martyna, G. J. Ab Initio and Empirical Model MD Simulation Studies of Solvent Effects on the Properties of N-Methylacetamide along a cis-trans Isomerization Pathway. J. Phys. Chem. B 2006, 110, 13523-13538. https://doi.org/10.1021/jp060999y

80. Mantz, Y. A.; Branduardi, D.; Bussi, G.; Parrinello, M. Ensemble of Transition State Structures for the Cis-Trans Isomerization of N-Methylacetamide. J. Phys. Chem. $B$ 2009, 113, 12521-12529. https://doi.org/10.1021/jp8106556

81. Li, P.; Chen, X. G.; Shulin, E.; Asher, S. A. UV Resonance Raman Ground and Excited State Studies of Amide and Peptide Isomerization Dynamics. J. Am. Chem. Soc. 1997, 119, 1116-1120. https://doi.org/10.1021/ja962058c

82. Xia, P.; Wang, C.; Qi, C. Theoretical Study on the Cyclization Mechanism of Dipeptides. Chin. J. Chem . 2013, 31, 813-818. https://doi.org/10.1002/cjoc.201300035

83. Grommet, A. B.; Feller, M.; Klajn, R. Chemical reactivity under nanoconfinement. Nature Nanotechnology 2020, 15, 256-271. https://doi.org/10.1038/s41565-020-0652-2

84. Charville, H.; Jackson, D.; Hodges, G.; Whiting, A. The thermal and boron-catalysed direct amide formation reactions: mechanistically understudied yet important processes. Chem. Commun. 2010, 46, 1813-1823. http://dx.doi.org/10.1039/B923093A

85. Yang, D.; Gaggioli, C. A.; Ray, D.; Babucci, M.; Gagliardi, L.; Gates, B. C. Tuning Catalytic Sites on $\mathrm{Zr}_{6} \mathrm{O}_{8}$ Metal-Organic Framework Nodes via Ligand and Defect Chemistry Probed with tert-Butyl Alcohol Dehydration to Isobutylene. J. Am. Chem. Soc. 2020, 142, 8044-8056. https://doi.org/10.1021/jacs.0c03175

86. Lundberg, H.; Tinnis, F.; Adolfsson, H. Direct Amide Coupling of Non-activated Carboxylic Acids and Amines Catalysed by Zirconium(IV) Chloride. Chem. Eur. J. 2012, 18, 3822-3826. https://doi.org/10.1002/chem.201104055

87. Lundberg, H.; Tinnis, F.; Adolfsson, H. Titanium(IV) Isopropoxide as an Efficient Catalyst for Direct Amidation of Nonactivated Carboxylic Acids. Synlett 2012, 23, 2201-2204. 
88. Tinnis, F.; Lundberg, H.; Adolfsson, H. Direct Catalytic Formation of Primary and Tertiary Amides from Non-Activated Carboxylic Acids, Employing Carbamates as Amine Source. Adv. Synth. Catal. 2012, 354, 2531-2536. https://doi.org/10.1002/adsc.201200436 